\title{
Editorial
}

\section{Nos Bastidores da Editoração}

Mais importante que a ciência é o seu resultado, uma resposta provoca uma centena de perguntas

Jacob Levy Moreno

Inspirada pelas palavras de Jacob Levy Moreno, penso no que move os atores envolvidos com os bastidores da editoração científica e me remeto a reflexões indissociáveis do processo da construção do saber. As motivações subjacentes a esta prática parecem estar calcadas no "anseio epistemofílico", típico dos adeptos à busca do conhecimento, que tem provavelmente suas raízes nas primeiras experiências de curiosidade frente ao mundo e cujo processo de descoberta traz mais gratificação do que o produto final em si. Embora este produto seja efetivamente a contribuição relevante do pesquisador para a comunidade científica, as etapas envolvidas em sua criação e os seus desdobramentos são os combustíveis que garantem o funcionamento da engrenagem acadêmica e lhe conferem as características dinâmica, aberta e dialética.

Uma das atribuições do editor é gerenciar os diferentes interesses envolvidos nesse fecundo processo e levar a público a organização de seu produto final. Findo cada número, novo processo se inaugura com novas contribuições e ressonâncias dos resultados anteriores. Em se tratando de um fenômeno eminentemente humano, é de se esperar que reações plurais decorrentes da expectativa, frustração ou conquista estejam presentes nos referidos bastidores. Nesse fluxo, formado pela atuação de uma intrincada rede responsável pela agilidade da tramitação editorial e que consiste nas relações interdependentes dos diversos atores - autores, editores, pareceristas ad hoc, conselheiros e órgãos de fomento, dentre outros -, o editor passa por momentos nos quais apenas a solidão o acompanha em suas decisões. Concebo este processo aberto e dialético da editoração científica como um espaço dos mais profícuos em trocas intelectuais que, menos que julgar a adequação e a qualidade dos produtos candidatos a publicação, ensejam uma oportunidade ímpar de aprendizagem, de interlocução com os pares, de aprimoramento teórico e metodológico dos estágios da investigação que são, em última instância, a própria essência da construção do conhecimento científico, é ciência in natura. Este continuum de construção do saber culmina com a publicação dos artigos aprovados, cujo objetivo é o de compartilhar seu produto final e o submeter à apreciação dos pares da comunidade científica mais ampla.

A revista Psicologia: Teoria e Pesquisa tem apoiado e aderido a propostas resultantes de iniciativas tais como a da BVS - Biblioteca Virtual em Saúde-Psicologia que reflete a postura do cientista comprometido com a dádiva do dar, receber e retribuir e, em nome da democratização do acesso à informação vem mobilizando os editores da área de Psicologia no Brasil e na América Latina, para integrarem um espaço virtual aberto, de acesso livre: a PePSIC. Cabe destacar, nessa esteira rumo ao progresso científico, a notícia da criação da Associação Brasileira de Editores Científicos na área de Psicologia - ABECiP ocorrida em São Paulo no dia 10 de março de 2006, cujo escopo principal é promover o aumento da qualidade e visibilidade da produção intelectual publicada em periódicos científicos da área de Psicologia.

Por seu turno, informamos aos nossos caros leitores que estamos trabalhando no sentido de converter nossos trâmites editoriais em tramitação eletrônica. Entendemos que, com isso, além da agilidade que será conferida ao funcionamento da revista, poderemos ousar dar passos maiores tais como, quem sabe, ter periodicidade trimestral.

Este número está composto por artigos de autores nacionais e internacionais que abordam questões referentes ao desenvolvimento humano, psicologia da saúde, psicologia social, psicologia da religião, história da psicologia, psicologia escolar e da aprendizagem, processos psicológicos básicos e neuropsicologia, bem como uma resenha sobre psicologia jurídica.

Assim, Suely Guimarães e Fabiana Gauy tratam de comparar a otimização de procedimentos de avaliação do comportamento de crianças com base em relatos maternos, em unidade de saúde mental infanto-juvenil. Daniela Lewandowski e César Piccinini procuram examinar semelhanças e diferenças de expectativas e sentimentos entre adolescentes e adultos frente à primeira experiência de paternidade. Caroline Dal Ri Kipper e Rita de Cássia Lopes investigam o fenômeno de tornar-se avó e sua relevância no processo de individuação. Robert-Vincent Joule e Ângela Almeida propõem princípios de ação que otimizam as práticas educativas, na perspectiva da psicologia do compromisso. Maria Suzana Menin trata de desvelar representações, estereótipos e preconceitos mascarados pelas normas sociais de grupos de referência.

Angela Oliva, Emma Otta e Fernando Ribeiro, Fívia Lopes, Maria Emília Yamamoto, Maria Lúcia Seidl de Moura e Vera Silvia Bussab apresentam uma breve história das principais transformações do conceito de mente em um prisma evolucionista. Geraldo José de Paiva discute o tema da educação religiosa oferecida pelo Estado face às condições psicológicas adequadas para tanto. Tatiane Dias e Sônia Enumo avaliaram os efeitos de programas de criatividade para alunos com dificuldade de aprendizagem por meio de procedimentos tradicional e assistido. Flávia Silveira e Marisa Neves discutem a inclusão escolar de crianças com deficiência múltipla de acordo com as concepções que pais e professores têm sobre a mesma.

Por sua vez, Angela Santa-Clara e Alina Spinillo lançam reflexões sobre os processos cognitivos de inferir e de argumentar em seus pontos de convergência; Bianca de Queiroga, Michelly Lins e Mirella Pereira estudam a relação entre consciência morfossintática e desempenho ortográfico em crianças do ensino fundamental. Luiz Carlos Albuquerque e Francynete Melo e Silva investigam os efeitos de histórias experimentais discrepantes das contingências sobre o seguir regras. Roberto Colom e Carmen Flores discutem as evidências empíricas derivadas da análise entre memória de trabalho e o fator geral de inteligência. Flavia Costa, Izabel Campos e Roberto Cruz fazem uma resenha sobre o livro "Psicologia Jurídica no Brasil" e sua relevância para a atuação do psicólogo no campo jurídico.

Por fim, quando concluíamos os trabalhos de editoração do presente número, fomos surpreendidos com a triste 
notícia do falecimento da Professora Silvia Lane. Em uma homenagem póstuma, suas alunas Ana Bock e Maria da Graça Gonçalves noticiam o fato e traduzem a falta que a renomada Professora fará para Psicologia Social e para a ciência brasileira.

Espero que o presente número suscite no leitor centenas de indagações científicas...

\section{Maria Inês Gandolfo Conceição \\ Editora}

\section{Referência}

Moreno, J. L. (1914). Einladung zu einer Begegnung. Anzengruber Verlag: Viena.

\section{Conselho Editorial (2004 - 2006)}

Áderson Luiz Costa Junior (UnB)

Ana Cecília de Souza Bastos (UFBA)

Ana Cristina Costa de Figueiredo (UFRJ)

Ângela Maria de Oliveira Almeida (UnB)

Antonio Pedro de Mello Cruz (UnB)

Domingos Sávio Coelho (UnB)

Emmanuel Zagury Tourinho (UFPA)

Eveline Maria Leal Assmar (UGF)

Hartmuth Günther (UnB)

Jairo Eduardo Borges-Andrade (UnB)

Leandro de Lajonquière (USP)

Maria Fátima Olivier Sudbrack (UnB)

Maria Helena Leite Hunziker (USP)

Regina Helena Freitas Campos (UFMG)

Terezinha de Camargo Viana (UnB)

Valdiney Veloso Gouveia (UFPB) 